\title{
Mycotic aneurysm of the left ventricle
}

\author{
M. S. B E A R E \\ From Baguley Hospital, Manchester
}

Aneurysm of the left ventricle is usually due to infarction following coronary thrombosis. According to Muller (1962), 'Syphilis, tuberculous caseation, mediastinal abscess, rheumatic fever, infectious endocarditis, and granulomas have also been implicated infrequently as etiologic agents.' Trauma, including the effects of using the transventricular dilator in mitral valvotomy, has also been implicated. Björk (1965) described a case of congenital left ventricular aneurysm in which there was no direct communication between the aneurysm and the cavity of the left ventricle. But dissecting or false aneurysm of the left ventricle of mycotic origin appears not to have been previously described. At a symposium on cardiac surgery held at the Brompton Hospital last year when the management of aneurysms was being discussed, no one on the panel or in the audience knew of such a lesion. The rarity of the condition prompts me to describe the following case.

\section{CASE REPORT}

The patient was a 3-year-old boy who was referred to the clinic of Mr. J. F. Dark on 27 February 1958 from Professor Gaisford's Department at the Royal Manchester Children's Hospital, Pendlebury. He had been admitted to Pendlebury on 16 November 1957 with a diagnosis of osteomyelitis of the right femur (Fig. 1) which had cleared up under penicillin treatment. Three days after admission he had been found to have a systolic bruit and thrill with an enlarged liver and venous congestion ; pericarditis with effusion was diagnosed. The P.A. radiograph of the heart, taken on 11 December 1957, is shown (Fig. 2). When seen on 27 February 1958 his radiograph showed a bulge continuous with the shadow of the left ventricle, and a diagnosis of loculated pericardial effusion was made.

He was admitted to Park Hospital, Davyhulme, on 6 March 1958. There was no history of illness prior to the osteomyelitis and no history of contact with any infection. The patient was one of seven children. He was a normally developed child but was thin and pale. Hb $77 \%$, W.B.C.s 10,600 per c.mm. (neutrophils $44 \%$, lymphocytes $46 \%$, monocytes $5 \%$, eosinophils $5 \%$ ). Clinically the heart did not appear enlarged; the apex beat was palpable in the fourth intercostal space, $2.5 \mathrm{~cm}$. to the right of the midclavicular line. There was a systolic apical thrill. $A \times$ loud systolic murmur was heard along the left border N of the sternum. No pericardial rub was heard. There was no venous congestion or enlargement of the liver.

He was afebrile. The pulse was 140 per minute; it was regular.

Unfortunately the radiograph of that date is not $\vec{c}$ available and the best film available is that of $6 \mathrm{~d}$ January 1958 (Fig. 3), which shows an enlarged cardiac shadow with an opacity at the left border of the heart.

On 11 March 1958 he had some pain in the chest. $\overrightarrow{\mathscr{Q}}$

The question was raised whether the abnormal. shadow could be a mycotic cardiac aneurysm, and a cardio-angiogram was therefore performed on 13 O March ; it showed no communication between the bulge on the wall of the left ventricle and the cavity of the left ventricle. The dye passed through the hearto and pulmonary circulation in a normal fashion, and $\varrho$ the abnormal shadow did not indent the cavity of the $\overrightarrow{\vec{O}}$ left ventricle.

The diagnosis of encysted pericardial effusion was therefore thought to be correct, and operation to deal with this condition was decided on. Operation was delayed because the child had a purulent nasal discharge and also passed a round worm on 16 March, $\frac{O}{\mathcal{N}}$ but a left thoracotomy was performed on 24 March 1958.

FINDINGS AT OPERATION There was a very large, pulsatile, cystic swelling covering the whole of the front surface of the left ventricle. An adherent peri-윽 carditis was present. The swelling was about $7 \times 6 \mathrm{~cm}$. in size and could be emptied by firm compression; ito filled up again relatively slowly, suggesting a small

It was decided that it would be unwise to excise the aneurysm without arrest of the circulation. $N$ Accordingly the wound was closed and operation $\omega$ under hypothermia was planned for 28 March.

The patient vomited a lot from 24 to 26 Marche and had to have fluid replacement with $5 \%$ dextrose in 1/5 normal saline solution. There was no vomiting? after $26 \mathrm{March}$, and he took fluids normally by mouth.

At the second operation on $28 \mathrm{March}$, under hypothermia, the chest was opened through a trans-sternali incision. Slings were tightened around the venae $\frac{\mathcal{P}}{\mathbb{D}}$ cavae and the aneurysmal sac was opened. It was@ found that a dissecting aneurysm of the left ventricle had developed. The deeper layer of the aneurysm 

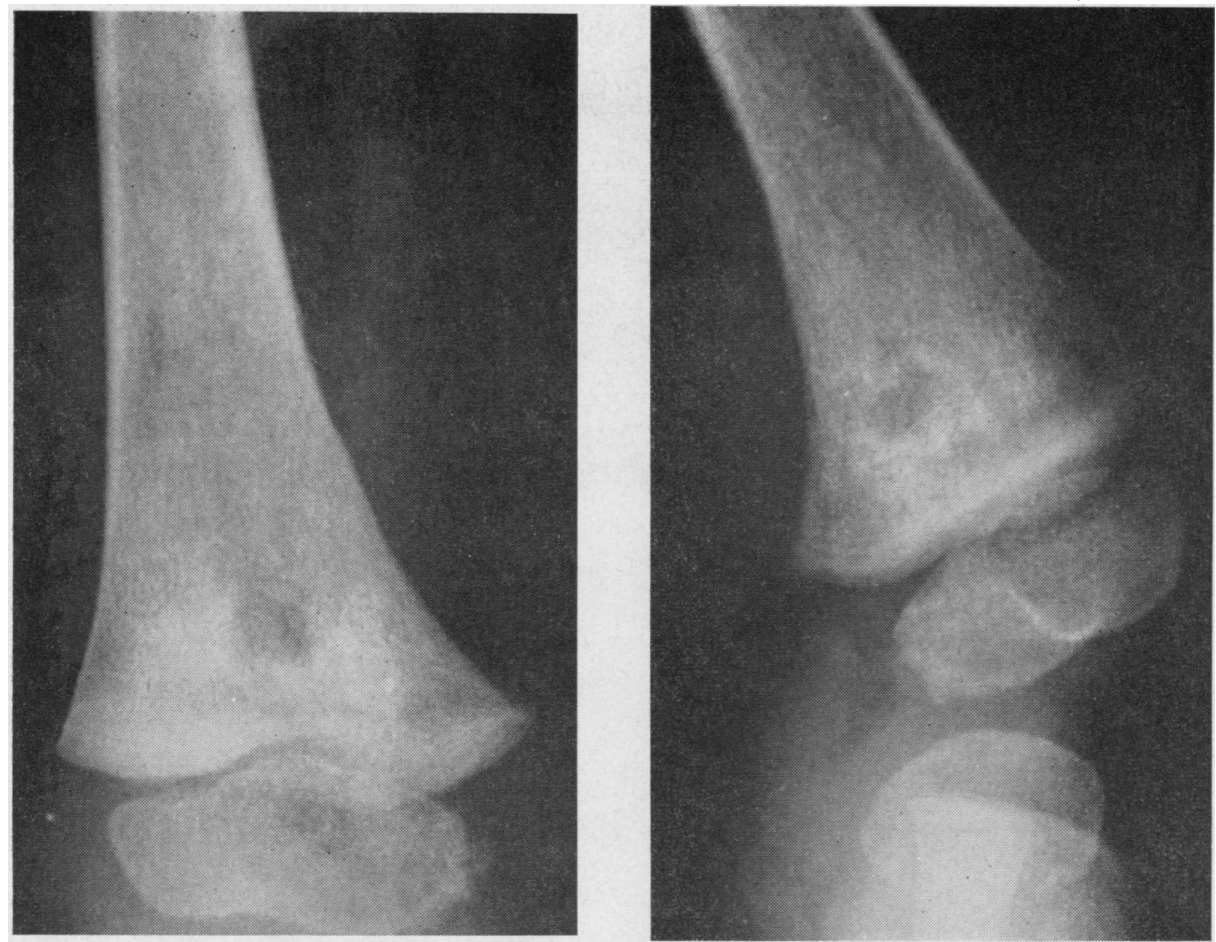

FIG. 1. Osteomyelitis right femur, 13 January 1958.

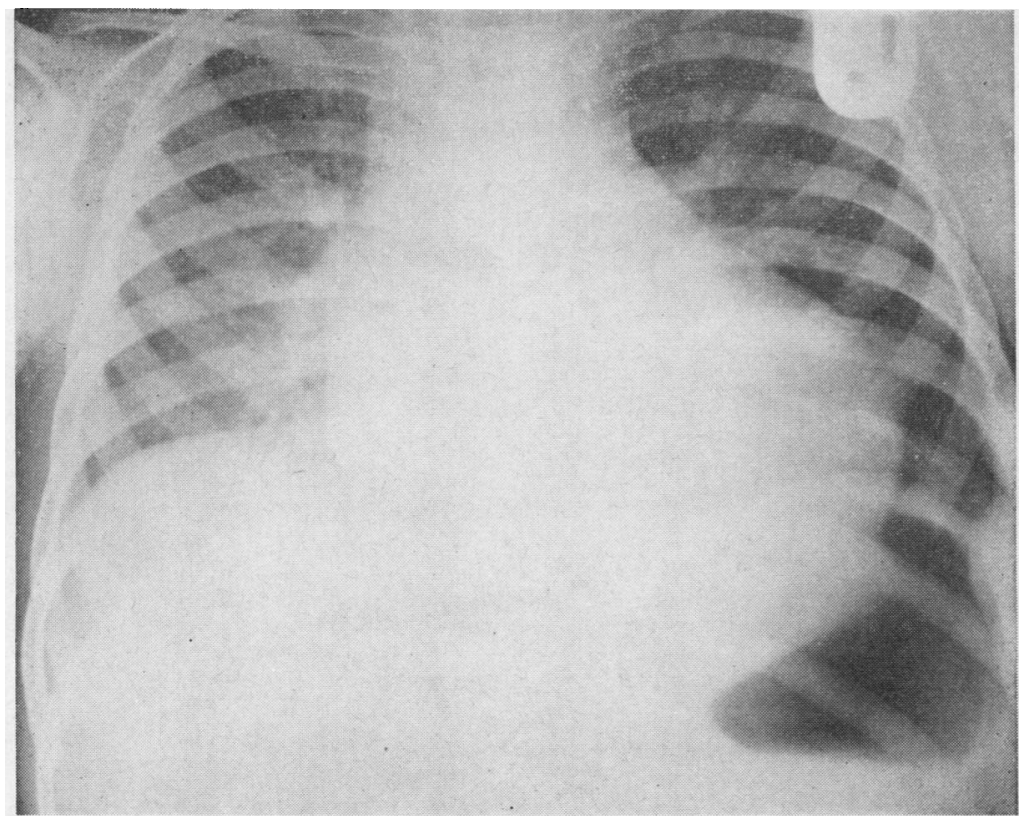

FIG. 2. Radiograph of the heart, 11 December 1957. 


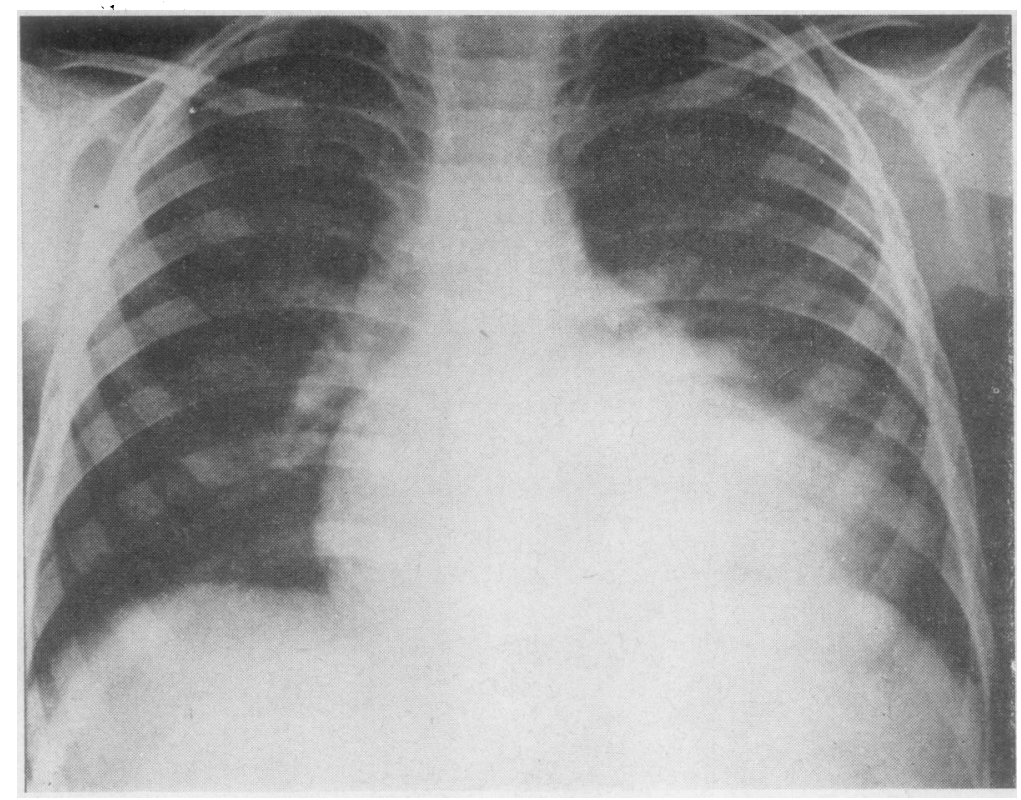

FIG. 3. Radiograph of the heart showing aneurysm, 6 January 1958.

consisted of good ventricular muscle, which contained three openings of only 2 or $3 \mathrm{~mm}$. in diameter which allowed communication between the cavity of the ventricle and the aneurysm. These openings were easily sutured while the circulation was arrested for 4 minutes and the aneurysmal sac was excised.

On 29 March the child developed electrolyte imbalance and was found to have a serum potassium of $7.6 \mathrm{mEq} / \mathrm{l}$, alkali reserve of $22 \mathrm{vol} . \%$, and blood urea of $130 \mathrm{mg}$. $/ 100 \mathrm{ml}$. He had a high temperature with rapid pulse, cold extremities, and twitching. In spite of intravenous infusion with dextrose and sodium lactate, he died on 30 March.

NECROPSY The necropsy report on the heart was as follows: 'The pericardium, both visceral and parietal, was roughened and the two layers were adherent to one another by fibrous and fibrinous material; on the outer aspect of the lateral wall of the left ventricle there was part of the wall of an aneurysm which had been folded over and sewn down; when the sutures were undone there were several small depressions in the base, two or three of which communicated with the cavity of the left ventricle just deep to the papillary muscle of the mitral valve; the wall of the left ventricle in this area was thinner than elsewhere and between the papillary muscle and the wall of the left ventricle there was some firm grey material; the aneurysmal wall was also grey and firm and did not resemble heart muscle but rather fibrous tissue; the remainder of the heart was normal (weight $160 \mathrm{~g}$.).

'There was also marked cerebral oedema.'
The pathological report on the portion of aneurys- $\mathbb{D}$ mal sac was as follows: 'This piece of tissue is $4.5 \Rightarrow$ $\mathrm{cm} . \times 5 \mathrm{~cm} . \times 2 \mathrm{~mm}$. thick. It consists of dense fibrous tissue lined by fibrin. No cardiac muscle can be seen and no active inflammation.'

Blood clot removed from the sac showed no evidence of infection or organization.

\section{CONCLUSION}

A case is described of a mycotic aneurysm of the left ventricle which developed in a child who was 3 suffering from acute osteomyelitis. I considered this aneurysm to be 'mycotic' because it developed, in a previously normal heart, during the courseo of an episode of acute osteomyelitis of the femur.

The aneurysm communicated by three smallo openings with the cavity of the left ventricle. SuchN a case does not appear to have been reported N previously. The method of repair of the aneurysm ${ }_{\sigma}^{\omega}$ is described.

I wish to thank Mr. J. F. Dark, F.R.C.S., for@ permission to publish this case.

\section{REFERENCES}

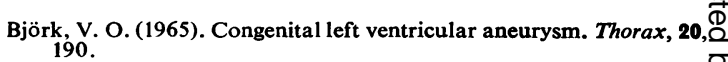

Muller, William H., Jr. (1962). In Gibbon's Surgery of the Chest. Saunders, Philadelphia. 